\title{
The IKK Complex, a Central Regulator of NF- $\kappa$ B Activation
}

\author{
Alain Israël \\ Unite de Signalisation Moleculaire et Activation Cellulaire, URA 2582 CNRS, Institut Pasteur, \\ 25 rue du Dr Roux, 75724 Paris Cedex 15, France \\ Correspondance: aisrael@pasteur.fr
}

The IKK kinase complex is the core element of the NF-кB cascade. It is essentially made of two kinases (IKK $\alpha$ and IKK $\beta$ ) and a regulatory subunit, NEMO/IKK $\gamma$. Additional components may exist, transiently or permanently, but their characterization is still unsure. In addition, it has been shown that two separate NF-кB pathways exist, depending on the activating signal and the cell type, the canonical (depending on IKK $\beta$ and NEMO) and the noncanonical pathway (depending solely on IKK $\alpha$ ). The main question, which is still only partially answered, is to understand how an NF- $\mathrm{BB}$ activating signal leads to the activation of the kinase subunits, allowing them to phosphorylate their targets and eventually induce nuclear translocation of the NF-kB dimers. I will review here the genetic, biochemical, and structural data accumulated during the last $10 \mathrm{yr}$ regarding the function of the three IKK subunits.

$\mathrm{N}_{\mathrm{t}}^{\mathrm{P}}$

F $\kappa \mathrm{B}$ represents a family of transcription factors that are normally kept inactive in the cytoplasm through interaction with inhibitory molecules of the IкB family. In response to multiple stimuli such as inflammatory cytokines, bacterial or viral products, or various types of stress, the IкB molecules become phosphorylated on two critical serine residues. This modification allows their polyubiquitination and destruction by the proteasome. As a consequence, free NF- $\kappa$ B enters the nucleus and activates transcription of a variety of genes participating in the immune and inflammatory response, cell adhesion, growth control, and protection against apoptosis.
The kinase(s) responsible for the phosphorylation of the IкB inhibitors remained elusive for many years, until the biochemical purification of a cytoplasmic high-molecularweight complex migrating around $700-900 \mathrm{kDa}$ and containing two related catalytic subunits, IKK $\alpha$ and IKK $\beta$ (Chen et al. 1996; Didonato et al. 1997). An additional component of the so-called IKK complex, NEMO/IKK $\gamma$ (thereafter referred to as NEMO), has subsequently been identified through genetic complementation of an NF- $\kappa$ B activation-defective cell line (Yamaoka et al. 1998) and sequencing of IKK-associated polypeptides (Rothwarf et al. 1998; Mercurio et al. 1999). Although NEMO does not have catalytic properties, cell lines

Editors: Louis M. Staudt and Michael Karin

Additional Perspectives on NF-кB available at www.cshperspectives.org

Copyright (C) 2010 Cold Spring Harbor Laboratory Press; all rights reserved; doi: 10.1101/cshperspect.a000158

Cite this article as Cold Spring Harb Perspect Biol 2010;2:a000158 
A. Israël

defective for NEMO do not activate NF- $\mathrm{B}$ in response to many stimuli, demonstrating the key role of this protein in activating the NF-кB pathway.

\section{THE KINASE SUBUNITS}

The two kinase subunits of the IKK complex, IKK $\alpha$ and IKK $\beta$, have been purified and cloned on the basis of their ability to phosphorylate the IкB inhibitors following biochemical purification of the complex (Mercurio et al. 1997). In addition, IKK $\alpha$ was cloned as an interactor of another kinase, NIK, which was later shown to be located upstream of IKK $\alpha$ in the noncanonical NF- $\kappa \mathrm{B}$ activation pathway (Regnier et al. 1997). IKK $\alpha$ and IKK $\beta$ show a similar structure (50\% sequence identity), and include an amino-terminal kinase domain, a helix-loop-helix (HLH) that functions in modulating IKK kinase activity, and a leucine zipper (LZ), whose role is to allow homo- or heterodimerization of the kinases (Fig. 1). In addition, IKK $\alpha$ shows a putative nuclear localization signal (Sil et al. 2004), possibly linked to its nuclear activity. IKK $\beta$ contains a ubiquitin-like domain whose function is currently unknown, but which does not seem to be recognized by the ubiquitin binding domains that have been tested (May et al. 2004).

The interaction domain between the kinase subunits and NEMO was identified as a small peptide at the carboxyl terminus of IKK $\alpha$ and IKK $\beta$. Interestingly, a cell-permeable 11 -amino-acid peptide derived from the carboxyl terminus of IKK $\beta$ (aa 735-745) behaves as an effective and specific inhibitor of NF- $\kappa \mathrm{B}$ by inhibiting the IKK-NEMO interaction and proved to be effective in two distinct experimental mouse models of acute inflammation (May et al. 2000).

The exact mechanism by which the kinase subunits become activated remains obscure. However, it is clear that to become active they need to be phosphorylated on two serine residues (Ser 177 and 181 for IKK $\beta$, and Ser 176 and 180 for $\mathrm{IKK} \alpha$ ) located in an activation loop, similar to a large number of other kinases (Mercurio et al. 1997; Delhase et al. 1999). This phosphorylation probably leads to a conformational change and to kinase activation. Mutation of these Ser to Ala prevents activation of the kinases whereas mutation to Glu (phosphomimetic) renders them constitutively active. The search for an upstream kinase of IKKs has been extremely lengthy. It now

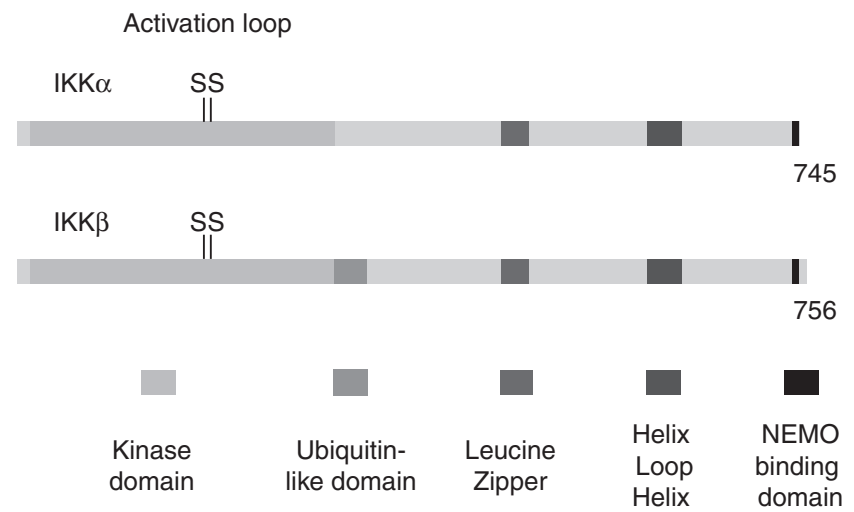

Figure 1. The kinase subunits. The domains of the two kinase subunits are indicated: The kinase domain is located at the amino-terminus (the activation loop is also shown: Amino acids 176-180 of IKK $\alpha$ and 177181 of IKK $\beta$ ). An ubiquitin-like domain (aa 307-384 in IKK $\beta$ ) is located carboxy-terminal to the kinase domain of IKK $\beta$ (but not IKK $\alpha$ ), and seems to be involved in the catalytic activity of IKK $\beta$. The function of the leucine zipper domain is to allow homo- or heterodimerization of the kinases. The role of the helix loop helix domain is less clear, but it seems to be involved in the modulation of the kinase activity. Finally a $\sim 40$ amino-acid region at the extreme carboxyl terminus of the kinases (aa 705-743) is required for their interaction with NEMO. 
seems clear that TAK1 behaves as an IKKK, at least in response to certain signals (NinomiyaTsuji et al. 1999; Wang et al. 2001). Indeed it has been shown that TAK1, which is also an upstream kinase for the JNK pathway, can phosphorylate IKK $\beta$ in the activation loop, that its down-regulation interferes with IKK activation, and that mutations in the TAK1 gene in Drosophila interfere with the NF- $\mathrm{KB}$ and JNK pathways (Vidal et al. 2001; Silverman et al. 2003). However it has also been shown that tissue-specific deletion of the TAK1 gene in the mouse does not lead to a defect in the NF- $\mathrm{B}$ response to B-cell antigen (Sato et al. 2005). TAK1 is normally associated with the cofactors TAB1 and TAB2 (or TAB3). Although TAB2 or TAB3 seems to be involved in NF- $\kappa \mathrm{B}$ activation, this does not seem to be the case for TAB1 (Shim et al. 2005). Another kinase, MEKK3, has also been suggested to act upstream of the IKK complex, as cells lacking MEKK3 are partially defective in NF- $\kappa \mathrm{B}$ activation in response to certain stimuli (Yang et al. 2001; Huang et al. 2004). In addition, it has been suggested that two pathways, dependent on either TAK1 or MEKK3, diverge downstream of IRAK1 in the NF- $\kappa$ B response to IL1 (Qin et al. 2006; Yao et al. 2007).

Finally, another possibility of activation of the kinases, which might be involved in NF$\kappa \mathrm{B}$ activation by certain viral proteins, such as HTLV1 Tax, is that there would be no specific requirement for an upstream kinase and that the ability of the IKKs to autophosphorylate and phosphorylate their dimerization partner might be activated by stimulus-dependent conformational changes or oligomerization, something that might in part depend on the presence of NEMO.

Although phosphorylation of IKK $\beta$ is necessary for activation of the canonical pathway, phosphorylation of $\mathrm{IKK} \alpha$ is not, though it is required for activation of the alternative pathway. As is often the case, the identity of the phosphatases that deactivate the kinases is relatively unclear. PP2A has been shown to dephosphorylate IKK $\beta$ in vitro (Didonato et al. 1997), whereas PP2C $\beta$ seems to be associated with IKK $\beta$ when overexpressed (Prajapati et al. 2004).
The similarity between the two kinase subunits, as well as their presence in the same complex, suggested that they would probably have overlapping functions. Unexpectedly, subsequent biochemical and genetic approaches have indicated that they have relatively distinct substrates and functions. This in turn relates to the existence of two NF- $\mathrm{B}$ pathways: The so-called canonical pathway is turned on by proinflammatory stimuli, such as TNF, IL1, or TLR ligands such as LPS, and is therefore involved in the innate response. This pathway essentially requires the IKK $\beta$ and NEMO subunit and leads to the rapid degradation of the ІкB inhibitory molecules. More recently, an alternative or noncanonical NF-кB pathway has been identified (Senftleben et al. 2001) and shown to be involved in the response to ligands such as BAFF, CD40 ligand, and LT $\beta$, and to be associated with lymphoid organogenesis. This pathway relies on the IKK $\alpha$ subunit and its upstream kinase NIK(Park et al. 2005), and does not require IKK $\beta$ nor NEMO. It leads to the slow partial degradation of the NF- $\kappa \mathrm{B}$ precursor subunit p100 and the association of the processing product $\mathrm{p} 52$ with relB, another member of the NF-кB family. In addition to its role in the alternative pathway, IKK $\alpha$ shows functions that are independent of the NF-кB pathway. For example, it has been shown to bind promoters of estrogen responsive genes, such as cyclin D1 and c-myc, and to activate their transcription by forming a transcription complex with the estrogen receptor $\mathrm{ER} \alpha$ and the coactivator AIB1/SRC-3 (Park et al. 2005).

Besides the I $\kappa \mathrm{B} \alpha$ inhibitors, other substrates of the IKK complex have been identified, including components of the NF- $\kappa \mathrm{B}$ cascade such as NEMO itself, relA, c-rel, CylD, and $\mathrm{Bcl10}$. The latter is a component of the NF-кB response to antigens in $\mathrm{T}$ cells (Thome and Tschopp 2002). Interestingly, IKK-mediated Bcl10 phosphorylation induces its degradation, resulting in down-regulation of NF- $\mathrm{KB}$ signaling (Lobry et al. 2007). This indicates that the IKK complex can behave both as a positive and a negative regulator of the cascade. Other substrates do not belong to the NF- $\mathrm{B}$ 
A. Israël

cascade. They include IRS-1, a component of insulin signaling (Nakamori et al. 2006). IRS-1 phosphorylation has been shown to participate in the mechanism by which TNF attenuates insulin signaling through activation of the IKK complex. Another substrate is TSC1, a component of a tumor suppressor complex (Lee et al. 2007). Phosphorylation of TSC1 by IKK $\beta$ activates the mTOR pathway, enhances angiogenesis, and results in tumor development. Finally, IKK has also been shown to phosphorylate and induce the degradation of the transcription factor FOXO3a, which plays an important role in controlling cell proliferation and survival, therefore promoting tumorigenesis (Hu et al. 2004).

\section{THE NEMO/IKK $\gamma$ REGULATORY SUBUNIT, AND THE FIRST STRUCTURAL DATA}

The third subunit of the IKK complex is a noncatalytic $48 \mathrm{kDa}$ protein, called NEMO/IKK $\gamma$ (Fig. 2). Although devoid of catalytic activity, NEMO is absolutely required for the canonical NF- $\kappa \mathrm{B}$ activation pathway. Structure prediction, confirmed by recent X-ray crystallography data, indicates that it is essentially a long parallel dimeric intermolecular coiled coil, except for the carboxyl terminus. The amino-terminal part of NEMO (aa 47-120 in human NEMO) is responsible for interaction with the kinase subunits (May et al. 2000). The X-ray structure of amino acids $44-111$ of NEMO bound to amino acids 701-746 of IKK $\beta$ has been reported recently (Rushe et al. 2008): It forms an asymmetrical four-helix bundle made of a parallel NEMO dimer, each monomer being a crescent shape $\alpha$-helix associated with two mainly helical IKK $\beta$ peptides, which do not interact with each other.

Interestingly, replacement of a phosphoacceptor Ser at position 68 by a phosphomimetic Glu decreases NEMO dimerization and reduces IKK $\beta$ binding (Palkowitsch et al. 2008). However, the kinase responsible for targeting Ser68 has not been unambiguously identified.

The rest of the molecule contains a first coiled coil (CC1, aa 100-196) and a second one (CC2, aa 255-291), followed by an LZ (LZ, aa 300-343) (see Fig. 1) and a carboxyterminal ZF (aa 394-419).

Another recent report describes the X-ray structure of the central region of NEMO associated with a fragment of the viral protein vFLIP (Bagnéris et al. 2008). vFLIP is a transactivator encoded by the Kaposi's sarcoma herpes virus (KSHV) whose interaction with NEMO activates $\mathrm{NF}-\kappa \mathrm{B}$. The structure indicates that the region encompassing aa 192-252 is another parallel intermolecular coiled coil. How vFLIP activates NF- $\mathrm{BB}$ cannot easily be deduced from this costructure.

A breakthrough in understanding the function of NEMO came when it was realized

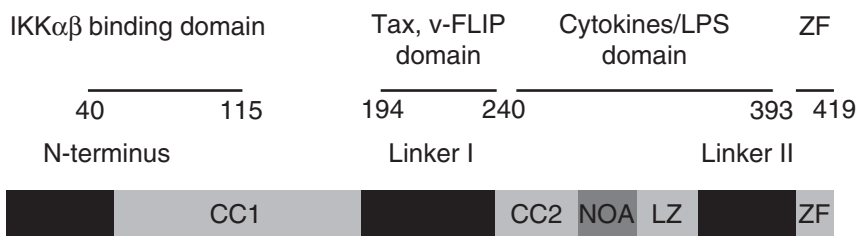

Figure 2. The NEMO molecule. Human NEMO is a 419-amino-acid dimeric molecule essentially structured under the form of a series of parallel intermolecular coiled coils (based on the available structural data). CC1, coiled coil 1; CC2, coiled coil 2; NOA, ubiquitin binding domain; ZF, Zinc Finger (and a second ubiquitin binding domain). The determination of the structure of linker 1 indicated that it is also structured as an intermolecular coiled coil. The structure of CC1 and linker II has not been determined yet. It must be stressed that the dimeric structure of NEMO is relatively unstable in the absence of interacting partners (kinases, polyubiquitin, ...). The region of interaction with some of these partners has been indicated: The amino terminus is involved in the interaction with the two kinases. Linker 1 is involved in the interaction with viral transactivators such as HTLV1 Tax and KSHV v-FLIP. The entire carboxy-terminal region is required for transmission of the signal, and the NOA and the ZF domains bind polyubiquitin chains. 
that nondegradative polyubiquitination of the Lys63-linked type played an important role in the NF- $\kappa$ B cascade. It was in 1996 that the requirement of nondegradative protein ubiquitination for IKK activation was first shown (Chen et al. 1996). Later on, biochemical purification and a reconstituted in vitro IKK activation system enabled the demonstration that TRAF6, an E3 ligase and a component of the NF- $\kappa$ B cascade downstream of proinflammatory molecules such as IL1 or LPS, associates with a dimeric E2 complex (Ubc13/Uev1a) to generate K63-linked polyubiquitin chains (Deng et al. 2000). This activity is necessary for IKK activation. Another necessary component of TRAF6-dependent NF- $\kappa \mathrm{B}$ activation turned out to be a complex containing the kinase TAK1 and its two cofactors TAB1 and TAB2 (Wang et al. 2001). This complex is able to phosphorylate IKK in a manner dependent on TRAF6 and Ubc13/Uevla (although the role of Ubc13 in IKK activation has been challenged [Habelhah et al. 2004; Yamamoto et al. 2006]). Later on it was shown that Lys63linked polyubiquitination of several components of the cascade seems to be a general feature of the response to different types of stimuli (Chen 2005). This is in particular the case for RIP1, a kinase and adaptor in the NF- $\kappa \mathrm{B}$ response to TNF. This modification serves to recruit proteins or protein complexes to polyubiquitinated substrates. Recently, it was shown that NEMO can specifically recognize Lys63-linked polyubiquitin chains and becomes itself ubiquitinated by the same type of chains following activation of the NF- $\kappa B$ cascade; these two properties seem to be required for NEMO activity (Tang et al. 2003; Ea et al. 2006; Wu et al. 2006a). As an example, the TNF cascade leading to NF- $\kappa \mathrm{B}$ activation is shown in Figure 3: TNF induces trimerization of the TNF receptor and leads to the recruitment of TRADD, the E3 ubiquitin-ligase TRAF2 (and/or TRAF5), and the kinase RIP1 (other molecules may be recruited but will not be discussed here). Lys63-linked polyubiquitination of RIP1 on Lys 377, possibly mediated by TRAF2 $/ 5$, leads to the recruitment of the TAK1/TAB1/TAB2 complex through the ubiquitin-binding Zinc Finger of TAB2. Through an unknown mechanism this leads to the activation of the TAK1 kinase. The IKK complex is also recruited to these $\mathrm{K} 63$ polyubiquitin chains through the specific ubiquitinbinding domain of NEMO. Alternatively, NEMO ubiquitination might directly recruit the TAK1 complex, allowing it to phosphorylate and activate the IKKs. Irrespective of the precise mechanism, activated TAK1 phosphorylates IKK $\beta$ on its activation loop, leading to its activation and to phosphorylation of the inhibitor $\mathrm{I} \kappa \mathrm{B} \alpha . \mathrm{I} \kappa \mathrm{B} \alpha$ is then polyubiquitinated through Lys48-linked polyubiquitin chains and degraded by the proteasome.

The importance of the ability of NEMO to bind ubiquitin has been confirmed by mutagenesis, as well as by the analysis of the mutations found associated with human pathologies (see the following discussion). Indeed, mutations in the domain of NEMO allowing recognition of K63-linked polyubiquitin chains (at aa 311, 315, 319) have been found in patients affected with EDA-ID. Database search allowed us to narrow down the region of NEMO involved in binding to ubiquitin to a small 30-40 aa domain located in the middle of the LZ domain, through identification of four other proteins that contain a similar region and also bind K63 linked polyubiquitin chains: optineurin and ABIN-1,2,3 (Sebban et al. 2006; Wagner et al. 2008). This region has been termed NOA/UBAN/NUB. Mutations in conserved residues interfere with binding of these proteins to ubiquitin, but the functional consequences are unclear in the case of ABINs as their actual function is still a matter of debate. Regarding optineurin, it has been shown recently that it acts as a negative regulator of TNF-induced NF- $\mathrm{BB}$ activation by competing with NEMO for binding to polyubiquitin chains (Zhu et al. 2007).

Very recently, a combination of X-ray and NMR analysis revealed the structural basis for recognition of polyubiquitin by the NOA domain (Lo et al. 2009). The data show that the region encompassing aa 265-330 forms a parallel intermolecular coiled coil with a kink at residue Pro299, which marks the boundary 
A. Israël

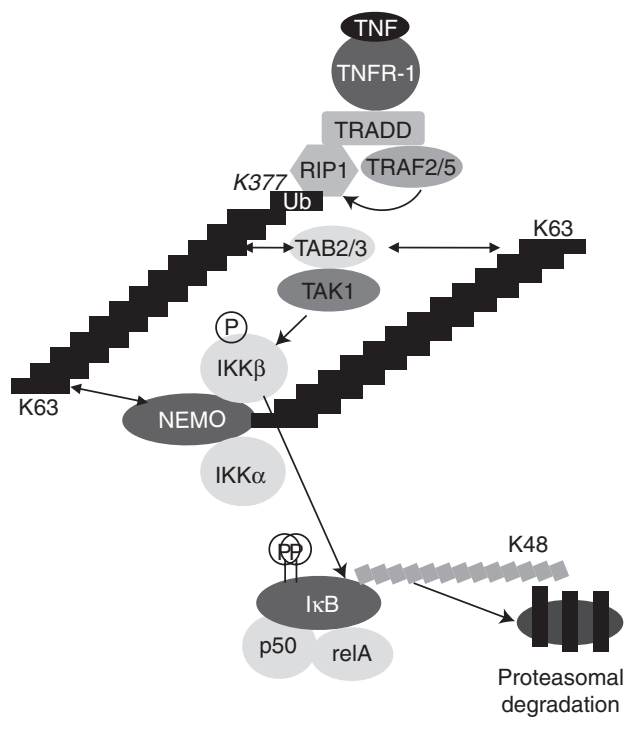

between the CC2 and LZ domains. A combination of mutagenesis and NMR analysis of a NOA-K63 diubiquitin complex reveals that diubiquitin is positioned perpendicular to the coiled coil and that each ubiquitin contacts both chains of a NEMO dimer. In addition, each ubiquitin interacts asymmetrically with NEMO. Interestingly, NEMO can also bind linear polyubiquitin with a much higher affinity and with a slightly different surface of contact. The physiological significance of this observation is currently unclear. However, it must be noted that a recent report (Tokunaga et al. 2009) describes the characterization of a dimeric E3 ligase made of two ring finger proteins, HOIP and HOIL-1L, which is able to generate linear polyubiquitin chains and to attach them to NEMO, onto Lys 285 and 309. This E3 ligase activity seems to be necessary for an NF-кB pathway which is independent of Ubc13.
Figure 3. The NF- $\kappa \mathrm{B}$ response to TNF. TNF induces trimerization of the TNF receptor, leading to the recruitment of TRADD, the E3 ubiquitin-ligase TRAF2 (and/or TRAF5), and the kinase RIP1 (other recruited molecules have been omitted for simplicity). K63-linked polyubiquitination of RIP1 on Lys 377 , possibly mediated by TRAF2/5 (curved arrow), leads to the recruitment of the TAK1/TAB1/ TAB2 complex through the ubiquitin-binding zinc finger of TAB2 (TAB2 can be replaced by TAB3, and TAB1 has been omitted for clarity). Through an unknown mechanism, this leads to the activation of the TAK1 kinase. The IKK complex is also recruited to these K63 polyubiquitin chains through the ubiquitin-binding domain of NEMO, allowing TAK1 to phosphorylate and activate the IKKs. K63-linked polyubiquitination of NEMO has been observed, but its actual role is currently unclear. One possibility is that it allows recruitment of the TAK1 complex in close proximity to the IKK kinase subunits, allowing their activation by TAK1; alternatively it might allow NEMO oligomerization through cross-recognition by its own ubiquitin binding domain. Whatever the exact mechanism of activation of the IKKs, they eventually phosphorylate

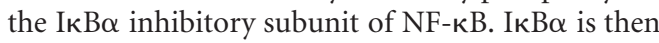
polyubiquitinated through Lys48-linked polyubiquitin chains by the $\beta$-TrCP E3 ubiquitin ligase, leading to its degradation by the proteasome and to nuclear translocation of free NF- $\mathrm{\kappa B}$ dimers, ultimately ending in activation of NF- $\kappa \mathrm{B}$ target genes.

Unpublished results from the group of F. Agou and M. Veron (Institut Pasteur) propose a different structural model whereby a dimeric NEMO molecule binds two K63linked polyubiquitination chains that run parallel to the NEMO coiled coil (submitted). In parallel, the same group has shown that the carboxy-terminal zinc finger of NEMO is also able to bind ubiquitin (Cordier et al. 2009). A further collaboration with the group of F. Agou allowed us to demonstrate that the specificity for K63 chains of NEMO does not depend on NEMO or ZF alone, but requires both domains (submitted). Therefore, the carboxy-terminal half of NEMO seems to represent a new type of bipartite K63-specific ubiquitin binding domain. Determination of the X-ray structure of a complex between this bipartite module and a K63-linked polyubiquitin chain will be necessary to understand how 
the specificity is achieved. Interestingly, this bipartite module is conserved in two other proteins, ABIN2 and optineurin. These results suggest that the main function of NEMO is to bring its associated kinases to polyubiquitinated targets. This, however, requires some level of specificity and a basal level of affinity between NEMO and its targets, as has been shown for RIP1 (Zhang et al. 2000).

Although the role of the ubiquitin binding ability of NEMO is reasonably clear, the role of NEMO polyubiquitination is far less obvious. NEMO ubiquitination through K63linked chains in response to multiple stimuli has been observed (see for example Tang et al. 2003; Zhou et al. 2004; Yamamoto et al. 2006), but the kinetics of this ubiquitination with regard to IKK activation remains unclear: Is it an early event required for activation of the IKK complex, or a late event involved in turning down NF- $\kappa \mathrm{B}$ activation? It could, for example, be imagined that NEMO ubiquitination allows direct recruitment of the TAK1 complex (instead of IKK and TAK1 complexes being corecruited to polyubiquitinated RIP1) (see Fig. 3), which could then phosphorylate and activate the NEMO-associated kinases. Alternatively, ubiquitinated NEMO might allow the recruitment of deubiquitinases such as CylD or A20, which have been described as negative regulators of $N F-\kappa B$, through the use of adaptor proteins such as the ABINs or TAX1BP1, which recognize K63-linked polyubiquitin chains (Mauro et al. 2006). From that point of view, one interesting observation is the fact that Ubc13-deficient cells are only mildly affected in NF- $\mathrm{BB}$ activation, whereas NEMO ubiquitination is strongly impaired (Yamamoto et al. 2006). The identification of the lysine residues which are targeted would probably help, but so far only a single site has been unambiguously identified by mass spectrometry: Lys 285 is ubiquitinated in response to the NOD2-RIP2 pathway (Abbott et al. 2004). A Lys residue located in the zinc finger at position 399 has also been postulated to be an important site of ubiquitination, essentially on the basis of mutagenesis experiments, but has never been confirmed by mass spectrometry analysis. Interestingly, this site is located in the middle of the ubiquitin binding surface of the zinc finger and its ubiquitination would interfere with NEMO binding to ubiquitin.

NEMO ubiquitination probably implies that it somehow needs to be deubiquitinated. A K63-specific deubiquitinase, CylD, has been found to interact with NEMO and to behave as a negative regulator of the NF- $\mathrm{B}$ pathway (Sun 2008). CylD can deubiquitinate NEMO in vitro. Therefore it was postulated that CylD inhibits the NF- $\mathrm{B}$ cascade by deubiquitinating specific substrates such as NEMO, RIP1, or others. Unfortunately, at the moment the identity of the physiological substrates of CylD is still unclear. Incidentally, other deubiquitinases such as A20 or Cezanne show the same K63 specificity and down-regulate the NF-кB pathway, but their exact substrates have not been identified yet (Sun 2008).

Although NEMO seems to be essentially dedicated to the NF- $\kappa \mathrm{B}$ pathway, it has been shown recently that it also seems to bridge the $\mathrm{NF}-\kappa \mathrm{B}$ and the interferon regulatory factor (IRF) signaling pathways (Zhao et al. 2007). The IRF3/IRF7 pathway of the innate response to virus infection relies on two IKK-related kinases (TBK1 and IKKe), which phosphorylate the IRF3 and IRF7 transcription factors and allow their nuclear translocation and subsequent activation of their target genes. These two kinases belong to a complex that has been described to include one of three known additional subunits, TANK, NAP1, or SINTBAD (Chau et al. 2008). Zhao et al. showed that virus-induced activation of IRF3 and IRF7 requires NEMO, which acts upstream of the kinases TBK1 and IKKe (Zhao et al. 2007). The authors also demonstrate that NEMO does not directly interact with the two kinases, but binds TANK. The exact role of NEMO in this cascade remains, however, unclear.

\section{OTHER POST-TRANSLATIONAL MODIFICATIONS OF NEMO}

Although NEMO ubiquitination has been extensively discussed, few reports deal with 
A. Israël

NEMO phosphorylation. IKK-dependent phosphorylation of NEMO on Ser 31, 43, 68, and 376 has been suggested to regulate NF- $\mathrm{B}$ activity, but these phosphorylation events have never been confirmed by mass spectrometric analysis (Carter et al. 2003; Palkowitsch et al. 2008). On the other hand, some other phosphorylation sites have been identified by global proteomewide mass spectrometric analysis, but their actual significance remains unclear.

In parallel, a specific NF- $\mathrm{B}$ activating signal, DNA damage, has been studied in detail and has revealed the role of a further modification of NEMO, sumoylation. It was first shown that double-strand breaks induce NF-кB through an ATM-IKK pathway, raising the question of how a nuclear signal could trigger a cytoplasmic response (Wu and Miyamoto 2007). The conclusion of a series of studies is now that NF- $\kappa \mathrm{B}$ activation by DNAdamaging agents is probably mediated by the conjunction of two convergent pathways: DNA damage-induced ATM activation and a parallel stress pathway that causes SUMO-1 modification of NEMO to permit NF- $\mathrm{B}$ activation. Indeed it was shown that a sumoylated form of NEMO accumulated in the nucleus in response to genotoxic stress, and that this form of NEMO was apparently free (Huang et al. 2003). The sites of sumoylation have been identified as Lys 277 and 309. Additional proteins, PIDD ( p53 induced protein with a death domain) and RIP1, were found to associate with NEMO in the nucleus, and to favor its sumoylation, although their exact role remains unclear (Janssens et al. 2005; Wu et al. 2006b). NEMO sumoylation is ATM-independent, but to allow NF- $\kappa$ B activation, NEMO must then be phosphorylated by ATM on Lys 85, leading to its monoubiquitination and to the export of a NEMO-ATM complex out of the nucleus (Huang et al. 2003). How this leads to activation of the IKK complex remains unclear, although it might involve the ELKS protein (see the following discussion). More recently the SUMO ligase responsible for NEMO sumoylation has been identified as PIASy (Mabb et al. 2006). The interaction between PIASy and NEMO is increased by genotoxic stress, and occurs in the nucleus; NEMO-PIASy and NEMO-IKK interactions are mutually exclusive. One may wonder what is the role of NF- $\kappa \mathrm{B}$ activation in response to DNA damaging agents. A series of reports suggest that NF- $\kappa \mathrm{B}$ activation inhibits cell death induced by DNA-damaging anticancer drugs and radiation and thus facilitates malignant cell survival and growth.

\section{NEMO AND THE FIRST NF- $\mathrm{B}$ LINKED HUMAN GENETIC DISEASES}

In 2000, the first human genetic diseases associated with mutations in the NF- $\kappa \mathrm{B}$ pathway were identified (Smahi et al. 2000). Two distinct $\mathrm{X}$-linked human diseases, incontinentia pigmenti (IP) and anhidrotic ectodermal dysplasia associated with immunodeficiency (EDA-ID), have been linked to NEMO dysfunction, providing a unique view of the role that NF- $\mathrm{B}$ plays in human development, skin homeostasis, and innate/acquired immunity.

\section{Loss of Function Mutations of NEMO Results in IP}

IP is a severe X-linked (the IKBKG gene encoding NEMO is located in $\mathrm{Xq} 28$ ) genodermatosis that is lethal for males early during development. In females, the most characteristic feature of the disease is a dermatosis that usually begins after birth and evolves according to a stereotyped sequence. In addition to the manifestations at the epidermis, IP patients also suffer from ophthalmologic, odontological (missing or deformed teeth) and, in rare cases, neurological problems. Interestingly, $85 \%$ of the patients show the same deletion that results in an inactive NEMO truncation product and a complete loss of NF- $\kappa \mathrm{B}$ activation by most known stimuli.

The complex skin phenotype of female IP patients is difficult to interpret, and it is impossible to cover all the possible explanations in this review (Smahi et al. 2002). NEMO knockout mice have been engineered by several groups (Makris et al. 2000; Rudolph et al. 2000; Schmidt-Supprian et al. 2000) and the phenotype of these mice is apparently similar to that of IP patients. Male mice die very early during 
embryogenesis (E12.5) from massive liver apoptosis, which is characteristic of a global defect in NF-кB activation. It is, however, not known whether liver apoptosis is also responsible for male lethality in IP patients.

\section{Hypomorphic Mutations of NEMO Results} in EDA-ID

As indicated above, complete NEMO loss of function is embryonic lethal for males but females can survive, showing a complex phenotype because of their mosaic character regarding $\mathrm{X}$-inactivation. More interestingly in terms of understanding the role played by NF- $\mathrm{B}$ in humans, hypomorphic NEMO mutations allow affected males to survive, and they show a pathology directly caused by a reduced response of the NF- $\kappa \mathrm{B}$ cascade. This pathology, anhidrotic EDA-ID (also known as HED-ID, OMIM \# 300291), associates the previously known symptoms of EDA (absence of sweat glands, sparce scalp hair, and missing teeth) with immunodeficiency (Doffinger et al. 2001). EDA is caused by mutations in several components of the EDA/EDAR cascade (EDA is a member of the TNF family and EDAR is its receptor), which is involved in the formation of ectodermal derivatives, and signals through NEMO and NF- $\kappa$ B. The mutations affecting NEMO interfere with both the EDA/EDAR cascade and the NF-кB-dependent pathways involved in the innate and acquired immune response. Mutations leading to EDA-ID have been shown to cover the entire NEMO coding region, and are essentially missense mutations and small deletions (Fusco et al. 2008; Hanson et al. 2008). Some patients carrying NEMO mutations show infectious susceptibility to specific pathogens, whereas others associate EDA-ID with osteopetrosis and lymphedema. The relevance to NF- $\kappa$ B of these two last symptoms is, however, relatively unclear.

An intriguing question is whether IP and EDA-ID represent the extreme boundaries of a genetic continuum. Indeed, depending on the severity of the mutation in terms of NF- $\mathrm{B}$ response, male patients will show more or less severe pathologies linked to defective immune response and EDA/EDAR pathway, or will die before birth in the case of complete loss of function. However, caution should be taken when translating the severity of the mutation and its position in the molecule into a dissection of the functional domains of NEMO, as two independently isolated patients carrying the same mutation show different symptoms, emphasizing the influence of the genetic background (Doffinger et al. 2001; Jain et al. 2001).

\section{ARE THERE OTHER COMPONENTS IN THE IKK COMPLEX?}

First, it is important to mention that several types of complexes most likely exist in cells, although this has not been systematically studied: It has already been mentioned that IKK $\alpha$ dimers exist in the absence of NEMO and IKK $\beta$, but is it likely that complexes containing NEMO and a dimer of IKK $\beta$ also exist. In addition, free NEMO is also present in cells, independently of the DNA damage response (Fontan et al. 2007; Wu and Miyamoto 2007).

The exact stoichiometry of the IKK complex has not been unambiguously determined, and its apparent molecular weight in sizing columns $(600-800 \mathrm{kDa})$ does not help much, as it is essentially caused by the elongated shape of NEMO. Based on the most recent structural data, the stoichiometry is probably one NEMO dimer for two kinase subunits, but higher order structures may exist. As the IKK complex needs relatively harsh conditions to be purified, one may wonder whether other components exist, besides NEMO and the kinases. The literature has described a large number of potential candidates (see Table 1 in Sebban et al. 2006) identified through twohybrid screens or coimmunoprecipitation, but it is unclear whether any of these proteins is a bona fide permanent component of the IKK complex. Some of these proteins might just transiently interact with IKK, which would still make them important components of the cascade, but precludes their detailed description within the restricted space of this article. It is, however, 
A. Israël

worth mentioning the ELKS protein (Ducut Sigala et al. 2004). Identified as a component of the IKK complex by purification and mass spectrometry, ELKS, a $105 \mathrm{kDa}$ protein, is necessary for full NF- $\mathrm{B}$ activation, and seems to be involved in recruiting I $\mathrm{B} \alpha$ to the IKK complex. As discussed previously, ELKS also seems to be involved in the NF- $\kappa \mathrm{B}$ response to DNA damaging agents (Wu et al. 2006b).

Chaperones such as hsp90 and hsp70 have also been described as components of the IKK complex (Salminen et al. 2008). Hsp70 seems to behave as a NEMO-interacting inhibitor of NF-кB signaling, while hsp90 associated with its co-chaperone cdc37 behaves as a stabilizing factor of IKK through interaction between cdc37 and the kinase domains of IKK $\alpha$ and IKK $\beta$. However, hsp90 also interacts with other kinases and seems to be a general stabilizer of kinase domain folding.

\section{WHAT DO KO MICE TELL US ABOUT THE FUNCTION OF THE IKK SUBUNITS?}

This section does not intend to cover the detailed phenotypes observed in mice carrying null or mutant alleles of the components of the IKK complex, but to briefly mention how in vivo studies have advanced our knowledge of the function of these proteins. The consequences of NEMO inactivation or mutation have been essentially studied in human patients affected with IP or EDA-ID (see previous discussion). Regarding the kinase subunits, it rapidly became clear that they differ in their substrate specificities and, as a result, have distinct biological functions. Although IKK $\beta$ is a true I $\mathrm{B}$ kinase, IKK $\alpha$ is not, and shows other, not necessary NF- $\mathrm{B}$-related activities. IKK $\beta$ was originally considered as the essential subunit responsible for $\mathrm{NF}-\kappa \mathrm{B}$ response to cytokines and various pathogen-derived antigens, which was confirmed by subsequent studies; $\mathrm{KO}$ of IKK $\beta$ results in embryonic lethality because of massive hepatocyte apoptosis (Li et al. 1999b; Li et al. 1999c; Tanaka et al. 1999), a mark of complete NF- $\kappa \mathrm{B}$ inactivation. This confirms the major role of IKK $\beta$ in the NF- $\mathrm{B}$ response. However, compared for example with a NEMO
$\mathrm{KO}$, death occurs a few days later, suggesting the possibility that IKK $\alpha$ can partially compensate for the absence of IKK $\beta$. Compared to IKK $\beta$, the IKK $\alpha$ subunit seems to show much more diverse functions. As mentioned above, it does play a role, although probably minor, in the canonical NF- $\kappa \mathrm{B}$ cascade. Unexpectedly, it plays a prominent role in RANK-induced classical NF- $\kappa \mathrm{B}$ activation in mammary epithelial cells (Cao et al. 2001), through NF-кB-mediated optimal cyclin D1 induction. It is, however, unclear why it is specifically IKK $\alpha$ that regulates these events. Based on IKK $\alpha$ specificity for the p100 precursor of p52 and its prominent role in the noncanonical cascade (Senftleben et al. 2001), one might have expected specific immune defects affecting secondary lymphoid organs and B cells in IKK $\alpha$ KO mice. Unexpectedly, these $\mathrm{KO}$ mice die a few days after birth and show defects affecting multiple morphogenetic events, including limb and skeletal patterning, and show keratinocyte hyperproliferation without differentiation ( $\mathrm{Hu}$ et al. 1999; Li et al. 1999a; Takeda et al. 1999). Further studies concluded that IKK $\alpha$ controls keratinocyte differentiation, but that this pathway does not rely on NF- $\mathrm{B}$ nor on the kinase activity of IKK $\alpha$ ( $\mathrm{Hu}$ et al. 2001). More recently, the crucial nuclear role of $\mathrm{IKK} \alpha$ in this phenomenon was shown through the identification of a functional NLS in the IKK $\alpha$ kinase domain (Sil et al. 2004). Inactivation of this NLS represses keratinocyte differentiation, indicating that IKK $\alpha$ exerts its function within the nucleus of basal keratinocytes in the epidermis. It must be noted that the expected B-cell phenotype associated with a defect in IKK $\alpha$ could indeed be observed in experiments involving establishment of bone marrow chimera through transfer of IKK $\alpha$-deficient fetal liver cells (Kaisho et al. 2001).

Later on it was shown that IKK $\alpha$ can also be found in the nucleus in the absence of NEMO and IKK $\beta$, where it acts at different levels to regulates NF- $\kappa \mathrm{B}$-dependent and -independent gene expression (Gloire et al. 2006). It was first shown that TNF induces the recruitment of IKK $\alpha$, together with relA and CBP, onto the promoter of NF- $\mathrm{KB}$ target genes (such as 
I $\kappa \alpha$, IL-8, or IL-6), where it phosphorylates histone $\mathrm{H} 3$ on Ser10, triggering its subsequent CBP-mediated acetylation on Lys14, a crucial step in modulating chromatin accessibility (Anest et al. 2003; Yamamoto et al. 2003). A similar situation was observed following LPS treatment of macrophages (Park et al. 2006). IKK $\alpha$ was later shown to regulate additional steps of NF- $\kappa \mathrm{B}$-dependent gene transcription. First it allows derepression of NF- $\mathrm{B}$ target genes by phosphorylating the SMRT repressor, which is recruited by p 50 and p 52 homodimers, and inducing its nuclear export (together with HDAC3) and degradation (Hoberg et al. 2004). Then it phosphorylates chromatinbound p65 on Ser536, leading to the displacement of the SMRT-HDAC3 repressor activity and allowing p300 to acetylate p65 at Lys310, an event necessary for full transcription (Hoberg et al. 2006).

Unexpectedly, a similar type of activity of IKK $\alpha$ has been shown to be involved in the negative regulation of macrophage activation and inflammation and to represent a crucial element in limiting the inflammatory response to Gram-negative infection (Lawrence et al. 2005). The molecular basis of this activity of IKK $\alpha$ was its ability to act as a chromatin-bound relA carboxy-terminal kinase responsible for p65 turnover, in turn limiting macrophage activation and inflammation.

\section{REFERENCES}

Abbott DW, Wilkins A, Asara JM, Cantley LC. 2004. The Crohn's disease protein, NOD2, requires RIP2 in order to induce ubiquitinylation of a novel site on NEMO. Curr Biol 14: 2217-2227.

Anest V, Hanson JL, Cogswell PC, Steinbrecher KA, Strahl $\mathrm{BD}$, Baldwin AS. 2003. A nucleosomal function for IkB kinase a (IKKa) is essential for NF-kB dependent gene expression. Nature 423: 659-663.

Bagnéris C, Ageichik AV, Cronin N, Wallace B, Collins M, Boshoff C, Waksman G, Barrett T. 2008. Crystal structure of a vFlip-IKK $\gamma$ complex: Insights into viral activation of the IKK signalosome. Molecular Cell 30: 620-631.

Cao Y, Bonizzi G, Seagroves TN, Greten FR, Johnson R, Schmidt EV, Karin M. 2001. IKK $\alpha$ Provides an Essential Link between RANK Signaling and Cyclin D1 Expression during Mammary Gland Development. Cell 107: $763-775$
Carter RS, Pennington KN, Ungurait BJ, Ballard DW. 2003. In Vivo Identification of Inducible Phosphoacceptors in the IKK $\gamma /$ NEMO Subunit of Human IкB Kinase. J Biol Chem 278: 19642-19648.

Chau TL, Gioia R, Gatot JS, Patrascu F, Carpentier I, Chapelle JP, O'Neill LAJ, Beyaert R, Piette J, Chariot A. 2008. Are the IKKs and IKK-related kinases TBK1 and IKK- $\varepsilon$ similarly activated? Trends Biochem Sci 33: $171-180$.

Chen ZJ. 2005. Ubiquitin signalling in the NF-кB pathway. Nat Cell Biol 7: 758-765.

Chen ZJ, Parent L, Maniatis T. 1996. Site-specific phosphorylation of IkBa by a novel ubiquitination-dependent protein kinase activity. Cell 84: 853-862.

Cordier F, Grubisha O, Traincard F, Véron M, Delepierre M, Agou F. 2009. The zinc finger of NEMO is a functional ubiquitin-binding domain. J Biol Chem 284: 2902-2907.

Delhase M, Hayakawa M, Chen Y, Karin M. 1999. Positive and negative regulation of I $\mathrm{\kappa}$ B kinase activity through IKK $\beta$ subunit phosphorylation. Science 284: 309-313.

Deng L, Wang C, Spencer E, Yang LY, Braun A, You JX, Slaughter C, Pickart C, Chen ZJ. 2000. Activation of the I к B kinase complex by TRAF6 requires a dimeric ubiquitin-conjugating enzyme complex and a unique polyubiquitin chain. Cell 103: 351-361.

Didonato JA, Hayakawa M, Rothwarf DM, Zandi E, Karin M. 1997. A cytokine-responsive IkB kinase that activates the transcription factor NF-kB. Nature 388: 548-554.

Doffinger R, Smahi A, Bessia C, Geissmann F, Feinberg J, Durandy A, Bodemer C, Kenwrick S, Dupuis-Girod S, Blanche S, et al. 2001. X-linked anhidrotic ectodermal dysplasia with immunodeficiency is caused by impaired NF-кB signaling. Nat Genet 27: 277-285.

Ducut Sigala JL, Bottero V, Young DB, Shevchenko A, Mercurio F, Verma IM. 2004. Activation of transcription

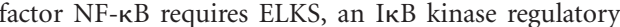
subunit. Science 304: 1963-1967.

Ea CK, Deng L, Xia ZP, Pineda G, Chen ZJ. 2006. Activation of IKK by TNF $\alpha$ Requires Site-Specific Ubiquitination of RIP1 and Polyubiquitin Binding by NEMO. Mol Cell 22: $1-13$.

Fontan E, Traincard F, Levy SG, Yamaoka S, Veron M, Agou F. 2007. NEMO oligomerization in the dynamic assembly of the IкB kinase core complex. Febs J 274: 2540-2551.

Fusco F, Pescatore A, Bal E, Ghoul A, Paciolla M, Lioi MB, D’Urso M, Rabia SH, Bodemer C, Bonnefont JP, et al. 2008. Alterations of the IKBKG locus and diseases: An update and a report of 13 novel mutations. Hum Mutat 29: $595-604$.

Gloire G, Dejardin E, Piette J. 2006. Extending the nuclear roles of ІкВ kinase subunits. Biochem Pharmacol 72: 1081-1089.

Habelhah H, Takahashi S, Cho SG, Kadoya T, Watanabe T, Ronai Z. 2004. Ubiquitination and translocation of TRAF2 is required for activation of JNK but not of p38 or NF-кB. Embo J 23: 322-332.

Hanson EP, Monaco-Shawver L, Solt LA, Madge LA, Banerjee PP, May MJ, Orange JS. 2008. Hypomorphic nuclear factor- $\mathrm{\kappa} \mathrm{B}$ essential modulator mutation database and reconstitution system identifies phenotypic and 
A. Israël

immunologic diversity. J Allergy Clin Immunol 122: 1169-1177.e1116.

Hoberg JE, Yeung F, Mayo MW. 2004. SMRT derepression by the I $\kappa$ B kinase $\alpha$ : A prerequisite to NF- $\kappa$ B transcription and survival. Mol Cell 16: 245-255.

Hoberg JE, Popko AE, Ramsey CS, Mayo MW. 2006. ІкB kinase $\alpha$-mediated derepression of SMRT potentiates acetylation of RelA/p65 by p300. Mol Cell Biol 26: 457-471.

Hu YL, Baud V, Delhase M, Zhang PL, Deerinck T, Ellisman M, Johnson R, Karin M. 1999. Abnormal morphogenesis but intact IKK activation in mice lacking the IKKa subunit of IkB kinase. Science 284: 316-320.

Hu Y, Baud V, Oga T, Kim KI, Yoshida K, Karin M. 2001. IKKa controls formation of the epidermis independently of NF-kB. Nature 410: 710-714.

Hu MC, Lee DF, Xia W, Golfman LS, Ou-Yang F, Yang JY, Zou Y, Bao S, Hanada N, Saso H, et al. 2004. IкB kinase promotes tumorigenesis through inhibition of forkhead FOXO3a. Cell 117: 225-237.

Huang TT, Wuerzberger-Davis SM, Wu ZH, Miyamoto S. 2003. Sequential modification of $\mathrm{NEMO} / \mathrm{IKK} \gamma$ by SUMO-1 and ubiquitin mediates NF- $\mathrm{BB}$ activation by genotoxic stress. Cell 115: 565-576.

Huang Q, Yang J, Lin Y, Walker C, Cheng J, Liu ZG, Su B. 2004. Differential regulation of interleukin 1 receptor and Toll-like receptor signaling by MEKK3. Nat Immunol 5: 98-103.

Jain A, Ma CA, Liu S, Brown M, Cohen J, Strober W. 2001. Specific missense mutations in NEMO result in hyper-IgM syndrome with hypohydrotic ectodermal dysplasia. Nature Immunol 2: 223-228.

Janssens S, Tinel A, Lippens S, Tschopp J. 2005. PIDD mediates NF-кB activation in response to DNA damage. Cell 123: $1079-1092$.

Kaisho T, Takeda K, Tsujimura T, Kawai T, Nomura F, Terada N, Akira S. 2001. IкB kinase $\alpha$ is essential for mature B cell development and function. J Exp Med 193: 417-426.

Lawrence T, Bebien M, Liu GY, Nizet V, Karin M. 2005. $\mathrm{IKK} \alpha$ limits macrophage NF- $\mathrm{\kappa B}$ activation and contributes to the resolution of inflammation. Nature 434: $1138-1143$.

Lee DF, Kuo HP, Chen CT, Hsu JM, Chou CK, Wei Y, Sun HL, Li LY, Ping B, Huang WC, et al. 2007. IKK $\beta$ suppression of TSC1 links inflammation and tumor angiogenesis via the mTOR pathway. Cell 130: 440-455.

Li QT, Lu QX, Hwang JY, Buscher D, Lee KF, Izpisua-Belmonte JC, Verma IM. 1999a. IKK1-deficient mice exhibit abnormal development of skin and skeleton. Genes Dev 13: 1322-1328.

Li QT, Van Antwerp D, Mercurio F, Lee KF, Verma IM. 1999b. Severe liver degeneration in mice lacking the IkB kinase 2 gene. Science 284: 321-325.

Li ZW, Chu WM, Hu YL, Delhase M, Deerinck T, Ellisman M, Johnson R, Karin M. 1999c. The IKKb subunit of IkB kinase (IKK) is essential for Nuclear Factor $\kappa$ B activation and prevention of apoptosis. J Exp Med 189: 1839-1845.

Lo YC, Lin SY, Rospigliosi CC, Conze DB, Wu CJ, Ashwel JD, Eliezer D, Wu H. 2009. Structural Basis for Recognition of Diubiquitins by NEMO. Mol Cell: doi:10.1016/j.mol- cel.2009.1001.1012.
Lobry C, Lopez T, Israel A, Weil R. 2007. Negative feedback loop in $\mathrm{T}$ cell activation through ІкB kinase-induced phosphorylation and degradation of Bcl10. Proc Natl Acad Sci 104: 908-913.

Mabb AM, Wuerzberger-Davis SM, Miyamoto S. 2006. PIASy mediates NEMO sumoylation and NF- $\kappa$ B activation in response to genotoxic stress. Nat Cell Biol 8: 986-993.

Makris C, Godfrey VL, Krahn-Senftleben G, Takahashi T, Roberts JL, Schwarz T, Feng LL, Johnson RS, Karin M. 2000. Female mice heterozygous for IKK $\gamma /$ NEMO deficiencies develop a dermatopathy similar to the human X-linked disorder incontinentia pigmenti. Mol Cell 5: 969-979.

Mauro C, Pacifico F, Lavorgna A, Mellone S, Iannetti A, Acquaviva R, Formisano S, Vito P, Leonardi A. 2006 ABIN-1 binds to NEMO/IKK $\gamma$ and co-operates with A20 in inhibiting NF-кB. J Biol Chem 281: 18482-18488.

May MJ, D’Acquisto F, Madge LA, Glockner J, Pober JS, Ghosh S. 2000. Selective inhibition of NF- $\kappa$ B activation by a peptide that blocks the interaction of NEMO with the I к B kinase complex. Science 289: 1550-1554.

May MJ, Larsen SE, Shim JH, Madge LA, Ghosh S. 2004. A novel ubiquitin-like domain in IкB kinase $\beta$ is required for functional activity of the kinase. J Biol Chem 279: 45528-45539.

Mercurio F, Zhu H, Murray BW, Shevchenko A, Bennett BL, Li J, Young DB, Barbosa M, Mann M, Manning A, et al. 1997. IKK-1 and IKK-2: Cytokine-activated IкB kinases essential for NF-кB activation. Science 278: 860-866.

Mercurio F, Murray BW, Shevchenko A, Bennett BL, Young DB, Li JW, Pascual G, Motiwala A, Zhu H, Mann M, et al. 1999. IkB kinase (IKK)-associated protein 1, a common component of the heterogeneous IKK complex. Mol Cell Biol 19: 1526-1538.

Nakamori Y, Emoto M, Fukuda N, Taguchi A, Okuya S, Tajiri M, Miyagishi M, Taira K, Wada Y, Tanizawa Y. 2006. Myosin motor Myolc and its receptor NEMO/ IKK- $\gamma$ promote TNF- $\alpha$-induced serine 307 phosphorylation of IRS-1. J Cell Biol 173: 665-671.

Ninomiya-Tsuji J, Kishimoto K, Hiyama A, Inoue J, Cao ZD, Matsumoto K. 1999. The kinase TAK1 can activate the NF- $\mathrm{KB}$ as well as the MAP kinase cascade in the IL-1 signalling pathway. Nature 398: 252-256.

Palkowitsch L, Leidner J, Ghosh S, Marienfeld RB. 2008. Phosphorylation of serine 68 in the IкB kinase (IKK)binding domain of NEMO interferes with the structure of the IKK complex and tumor necrosis factor- $\alpha$-induced NF-кB activity. J Biol Chem 283: 76-86.

Park KJ, Krishnan V, O’Malley BW, Yamamoto Y, Gaynor RB. 2005 . Formation of an IKK $[\alpha]$-Dependent Transcription Complex Is Required for Estrogen Receptor-Mediated Gene Activation. Mol Cell 18: 71-82.

Park GY, Wang X, Hu N, Pedchenko TV, Blackwell TS, Christman JW. 2006. NIK is involved in nucleosomal regulation by enhancing histone $\mathrm{H} 3$ phosphorylation by IKK $\alpha$. J Biol Chem 281: 18684-18690.

Prajapati S, Verma U, Yamamoto Y, Kwak YT, Gaynor RB. 2004. Protein phosphatase 2C $\beta$ association with the IкB kinase complex is involved in regulating NF- $\mathrm{B}$ activity. J Biol Chem 279: 1739-1746. 
Qin J, Yao J, Cui G, Xiao H, Kim TW, Fraczek J, Wightman P, Sato S, Akira S, Puel A, et al. 2006. TLR8-mediated NF- $\kappa B$ and JNK activation are TAK1-independent and MEKK3-dependent. J Biol Chem 281: 21013-21021.

Regnier CH, Song HY, Gao X, Goeddel DV, Cao Z, Rothe M 1997. Identification and characterization of an ІкB kinase. Cell 90: 373-383.

Rothwarf DM, Zandi E, Natoli G, Karin M. 1998. IKK-g is an essential regulatory subunit of the IkB kinase complex. Nature 395: 297-300.

Rudolph D, Yeh WC, Wakeham A, Rudolph B, Nallainathan D, Elia A, Potter J, Mak TW. 2000. Severe liver degeneration and lack of NF-kB activation in NEMO/IKK- $\gamma$ deficient mice. Genes Dev 14: 854-862.

Rushe M, Silvian L, Bixler S, Chen LL, Cheung A, Bowes S, Cuervo H, Berkowitz S, Zheng T, Guckian K, et al 2008. Structure of a NEMO/IKK-Associating Domain Reveals Architecture of the Interaction Site. Structure 16: $798-808$.

Salminen A, Paimela T, Suuronen T, Kaarniranta K. 2008. Innate immunity meets with cellular stress at the IKK complex: Regulation of the IKK complex by HSP70 and HSP90. Immunology Letters 117: 9-15.

Sato S, Sanjo H, Takeda K, Ninomiya-Tsuji J, Yamamoto M, Kawai T, Matsumoto K, Takeuchi O, Akira S. 2005. Essential function for the kinase TAK1 in innate and adaptive immune responses. Nat Immunol 6: 1087-1095.

Schmidt-Supprian M, Bloch W, Courtois G, Addicks K, Israël A, Rajewsky K, Pasparakis M. 2000. NEMO/IKK $\gamma$-deficient mice model Incontinentia Pigmenti. Mol Cell 5: 981-992.

Sebban H, Yamaoka S, Courtois G. 2006. Posttranslational modifications of NEMO and its partners in NF- $\mathrm{\kappa B}$ signaling. Trends Cell Biol 16: 569-577.

Senftleben U, Cao Y, Xiao G, Greten FR, Krahn G, Bonizzi G, Chen Y, Hu Y, Fong A, Sun SC, et al. 2001. Activation by IKK $\alpha$ of a second, evolutionary conserved, NF-к B signaling pathway. Science 293: 1495-1499.

Shim JH, Xiao C, Paschal AE, Bailey ST, Rao P, Hayden MS, Lee KY, Bussey C, Steckel M, Tanaka N, et al. 2005. TAK1, but not TAB1 or TAB2, plays an essential role in multiple signaling pathways in vivo. Genes Dev 19: $2668-2681$.

Sil AK, Maeda S, Sano Y, Roop DR, Karin M. 2004. IкB kinase- $\alpha$ acts in the epidermis to control skeletal and craniofacial morphogenesis. Nature 428: 660-664.

Silverman N, Zhou R, Erlich RL, Hunter M, Bernstein E, Schneider D, Maniatis T. 2003. Immune activation of NF-кB and JNK requires Drosophila TAK1. J Biol Chem 278: $48928-48934$.

Smahi A, Courtois G, Vabres P, Yamaoka S, Heuertz S, Munnich A, Israël A, Heiss NS, Klauck S, Kioschis P, et al. 2000. Genomic rearrangement in NEMO impairs NF-kB activation and is a cause of Incontinentia Pigmenti. Nature 405: 466-472.

Smahi A, Courtois G, Rabia SH, Doffinger R, Bodemer C, Munnich A, Casanova JL, Israël A. 2002. The NF-кB signalling pathway in human diseases: From incontinentia pigmenti to ectodermal dysplasias and immunedeficiency syndromes. Hum Mol Genet 11: 2371-2375.
Sun SC. 2008. Deubiquitylation and regulation of the immune response. Nat Rev Immunol 8: 501-511.

Takeda K, Takeuchi O, Tsujimura T, Itami S, Adachi O, Kawai T, Sanjo H, Yoshikawa K, Terada N, Akira S. 1999. Limb and skin abnormalities in mice lacking IKKa. Science 284: 313-316.

Tanaka M, Fuentes ME, Yamaguchi K, Durnin MH, Dalrymple SA, Hardy KL, Goeddel DV. 1999. Embryonic lethality, liver degeneration, and impaired NF-kB activation in IKKb-deficient mice. Immunity 10: 421-429.

Tang ED, Wang CY, Xiong Y, Guan KL. 2003. A role for

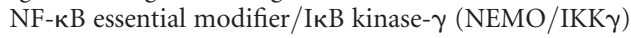
ubiquitination in the activation of the IкB kinase complex by tumor necrosis factor- $\alpha$. J Biol Chem 278: 37297-37305.

Thome M, Tschopp J. 2002. Bcl10. Curr Biol 12: R45.

Tokunaga F, Sakata S, Saeki Y, Satomi Y, Kirisako T, Kamei K, Nakagawa T, Kato M, Murata S, Yamaoka S, et al. 2009. Involvement of linear polyubiquitylation of NEMO in NF-кB activation. Nat Cell Biol 11: 123-132.

Vidal S, Khush RS, Leulier F, Tzou P, Nakamura M, Lemaitre B. 2001. Mutations in the Drosophila dTAK1 gene reveal a conserved function for MAPKKKs in the control of rel/ NF-кB-dependent innate immune responses. Genes Dev 15: 1900-1912.

Wagner S, Carpentier I, Rogov V, Kreike M, Ikeda F, Lohr F, Wu CJ, Ashwell JD, Dotsch V, Dikic I, et al. 2008. Ubiquitin binding mediates the NF- $\mathrm{KB}$ inhibitory potential of ABIN proteins. Oncogene 27: 3739-3745.

Wang C, Deng L, Hong M, Akkaraju GR, Inoue J, Chen ZJ. 2001. TAK1 is a ubiquitin-dependent kinase of MKK and IKK. Nature 412: 346-351.

Wu Miyamoto S. 2007. Many faces of NF- $\mathrm{kB}$ signaling induced by genotoxic stress. J Mol Med 85: 1187-1202.

Wu CJ, Conze DB, Li T, Srinivasula SM, Ashwell JD. 2006a. NEMO is a sensor of Lys 63-linked polyubiquitination and functions in NF-кB activation. Nat Cell Biol 8: 398-406.

Wu ZH, Shi Y, Tibbetts RS, Miyamoto S. 2006b. Molecular Linkage Between the Kinase ATM and NF- $к B$ Signaling in Response to Genotoxic Stimuli. Science 311: $1141-1146$.

Yamamoto Y, Verma U, Prajapati S, Kwak YT, Gaynor RB. 2003. Histone $\mathrm{H} 3$ phosphorylation by IKK $\alpha$ is critical for cytokine-induced gene expression. Nature 423: 655-659.

Yamamoto M, Okamoto T, Takeda K, Sato S, Sanjo H, Uematsu S, Saitoh T, Yamamoto N, Sakurai H, Ishii KJ, et al. 2006. Key function for the Ubc13 E2 ubiquitinconjugating enzyme in immune receptor signaling. Nat Immunol 7: 962-970.

Yamaoka S, Courtois G, Bessia C, Whiteside ST, Weil R, Agou F, Kirk HE, Kay RJ, Israël A. 1998. Complementation cloning of NEMO, a component of the IkB kinase complex essential for NF-kB activation. Cell 93: 1231-1240.

Yang J, Lin Y, Guo Z, Cheng J, Huang J, Deng L, Liao W, Chen Z, Liu Z, Su B. 2001. The essential role of MEKK3 in TNFinduced NF-кB activation. Nat Immunol 2: 620-624.

Yao J, Kim TW, Qin J, Jiang Z, Qian Y, Xiao H, Lu Y, Qian W, Gulen MF, Sizemore N, et al. 2007. Interleukin-1 


\section{A. Israël}

(IL-1)-induced TAK1-dependent Versus MEKK3-dependent NFкB activation pathways bifurcate at IL-1 receptor-associated kinase modification. $J$ Biol Chem 282: 6075-6089.

Zhang SQ, Kovalenko A, Cantarella G, Wallach D. 2000. Recruitment of the IKK signalosome to the p55 TNF receptor: RIP and A20 bind to NEMO (IKK $\gamma$ ) upon receptor stimulation. Immunity 12: 301-311.

Zhao T, Yang L, Sun Q, Arguello M, Ballard DW, Hiscott J, Lin R. 2007. The NEMO adaptor bridges the nuclear
factor-кB and interferon regulatory factor signaling pathways. Nat Immunol 8: 592-600.

Zhou H, Wertz I, O’Rourke K, Ultsch M, Seshagiri S, Eby M, Xiao W, Dixit VM. 2004. Bcl10 activates the NF-кB pathway through ubiquitination of NEMO. Nature 427: $167-171$.

Zhu G, Wu CJ, Zhao Y, Ashwell JD. 2007. Optineurin negatively regulates TNF $\alpha$ - induced NF- $\mathrm{B}$ activation by competing with NEMO for ubiquitinated RIP. Curr Biol 17: 1438-1443. 


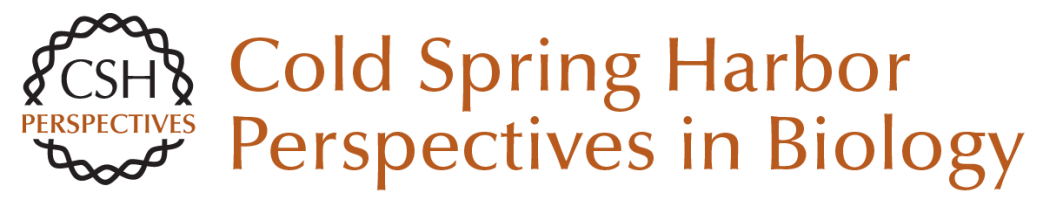

\section{The IKK Complex, a Central Regulator of NF-KB Activation}

Alain Israël

Cold Spring Harb Perspect Biol 2010; doi: 10.1101/cshperspect.a000158 originally published online September 23, 2009

\section{Subject Collection NF-kB}

Use of Forward Genetics to Discover Novel

Regulators of NF- $\mathrm{KB}$ Tao Lu and George R. Stark

Selectivity of the NF-kB Response Ranjan Sen and Stephen T. Smale

NF-KB in the Nervous System Barbara Kaltschmidt and Christian Kaltschmidt

Signaling to NF- $\kappa B$ : Regulation by Ubiquitination Ingrid E. Wertz and Vishva M. Dixit

Ubiquitination and Degradation of the Inhibitors of NF- KB

Naama Kanarek, Nir London, Ora Schueler-Furman, et al.

A Structural Guide to Proteins of the NF-KB Signaling Module

Tom Huxford and Gourisankar Ghosh

NF-kB in the Immune Response of Drosophila Charles Hetru and Jules A. Hoffmann

\section{Control of NF-kB-dependent Transcriptional}

Responses by Chromatin Organization Gioacchino Natoli
Oncogenic Activation of NF- $\mathrm{kB}$

Louis M. Staudt

The Regulatory Logic of the NF- $\mathrm{kB}$ Signaling

System Ellen O'Dea and Alexander Hoffmann

Roles of the NF- $k B$ Pathway in Lymphocyte

Development and Function

Steve Gerondakis and Ulrich Siebenlist

The IKK Complex, a Central Regulator of NF- $\mathrm{KB}$

Activation Alain Israël

NF- $\kappa B$ in the Nervous System

Barbara Kaltschmidt and Christian Kaltschmidt

The Nuclear Factor NF- $\kappa B$ Pathway in Inflammation

Toby Lawrence

NF- $\mathrm{KB}$ as a Critical Link Between Inflammation and Cancer Michael Karin

Specification of DNA Binding Activity of NF-KB Proteins

Fengyi Wan and Michael J. Lenardo

For additional articles in this collection, see http://cshperspectives.cshlp.org/cgi/collection/

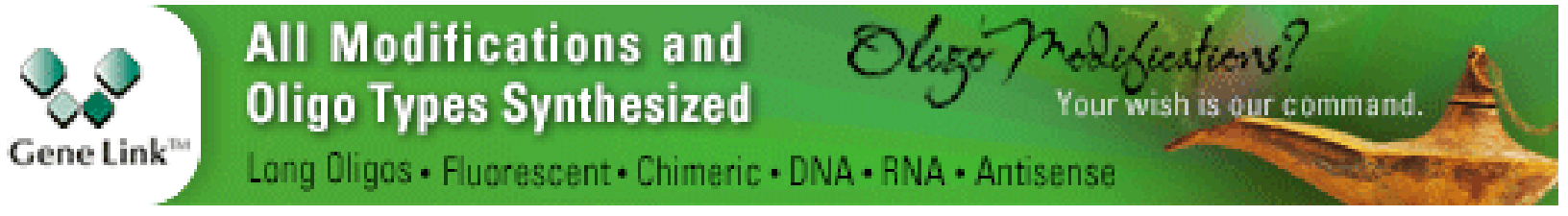

Copyright @ 2010 Cold Spring Harbor Laboratory Press; all rights reserved 